\title{
Atopik Dermatit Tanılı Çocuklarda Banyo Alışkanlıkları ve Egzama Şiddetine Etkisi
}

\section{Bath Habits in Children with Atopic Dermatitis and Its Effect on Severity of Eczema}

\author{
Didem Yayla Karakurt ${ }^{1}$ (D) Esra Yücel ${ }^{2}$ (D), Deniz Özçeker ${ }^{3}$, Ömer Faruk Beşer ${ }^{4}$ (1)
}

\begin{abstract}
${ }^{1}$ Sağıık Bilimleri Üniversitesi, Okmeydanı Eğitim Araştırma Hastanesi, Çocuk Sağlığı ve Hastalıkları Bilim Dalı, İstanbul, Türkiye ${ }^{2}$ Istanbul Üniversitesi, İstanbul Tıp Fakültesi, Çocuk Sağlı̆ı ve Hastalıkları, Çocuk İmmunoloji ve Alerji Bilim Dalı, İstanbul, Türkiye ${ }^{3}$ Sağlık Bilimleri Üniversitesi, Okmeydanı Eğitim Araştırma Hastanesi, Çocuk Alerji ve İmmünoloji, İstanbul, Türkiye ${ }^{4}$ Istanbul Üniversitesi-Cerrahpaşa, Cerrahpaşa Tıp Fakültesi, Çocuk Sağlığı ve Hastalıkları, Çocuk Gastroenteroloji, Hepatoloji ve Beslenme Bilim Dalı, İstanbul, Türkiye
\end{abstract}

ORCID ID: D.Y.K. 0000-0003-1428-3550; E.Y. 0000-0003-3712-2522; D.Ö. 0000-0002-0032-6727; Ö.F.B. 0000-0003-1927-7256

Attf/Citation: Yayla Karakurt D, Yucel E, Ozceker D, Beser OF. Atopik dermatit tanılı çocuklarda banyo alışkanlıkları ve egzama şiddetine etkisi. Çocuk Dergisi - Journal of Child 2020;20(3):83-88. https://doi.org/10.26650/jchild.2020.3.778936

Öz

Amaç: Atopik dermatit tanılı hastalarda banyo alışkanlıklarının ve nemlendirici kullanımının hastalığın şiddetine etkisinin saptanması ve ailelerin bu konudaki tutumlarının belirlenmesi amaçlandı.

Gereç ve Yöntem: Tanımlayıcı kesitsel tipteki çalışmamızda Okmeydanı EAH Çocuk Alerji Polikliniğine başvuran atopik dermatit tanılı hastaların annelerine banyo sıklığı, yıkanma şekli, banyo süresi, banyoda kullanılan ürünler ve nemlendirici kullanımı ile ilgili soruları içeren anket uygulanarak veriler toplandı. Atopik dermatitin ağırlığını belirlemek için Atopik Dermatit skorlaması SCORAD (SCORing Atopic Dermatitis) skoru kullanıldı. Hastalara ait serum total immunglobulin (Ig) $E$, eozinofil yüzdesi ve deri delme testi sonuçları hasta dosyasından elde edildi.

Bulgular: Çalışmaya 6 ay- 15 yaş arası 49'u erkek ve 51'i kız hastanın annesi katılmıştır. SCORAD skoruna göre hastalar gruplandırıldığında 48 hastanın hafif, 49 hastanın orta ve 3 hastanın ciddi atopik dermatiti (AD) olduğu görüldü. Atopik dermatit ağırlığı SCORAD’a göre gruplanan hastalarda banyo ile yıkanma oranı duş almaya oranla yüksek saptandı $(p=0,001)$. Kışın her gün yıkanma oranı SCORAD skor sonucu ağır dermatit ile uyumlu olanlarda; hafif ve orta olanlara $(\% 22,45)$ göre daha yüksek saptandı $(p=0,034)$. Nemlendirici kullanımı, sıklığı ve kullanılan ürünler ile AD ağırlığı arasında anlamlı ilişki bulunmadı.

Sonuç: Banyo şeklinde yıkanmanın duş almaya göre daha etkili olabileceği tespit edilmiştir. Atopik dermatit tedavisinde nemlendirici kullanımı ve ilaç tedavisine ek olarak yıkanma şekli ve kullanılan ürünler önem taşıyabilir, bu durum ayrıntılı değerlendirilmelidir.

Anahtar Kelimeler: Atopik dermatit, banyo, duş, egzama, SCORAD

\section{ABSTRACT}

Objective: This study, aimed to determine the effect of bathing habits and moisturizer use on the severity of atopic dermatitis in pediatric patients and determine the families' attitudes.

Material and Methods: In this descriptive cross-sectional study, data were collected by administering a questionnaire containing questions about bathing frequency, bathing duration, bathing methods, bath products used, and moisturizers used by mothers for children atopic dermatitis. The SCORing Atopic Dermatitis (SCORAD) score was used to determine the severity of atopic dermatitis. Serum total immunoglobulin (Ig) E, eosinophil percentage, and skin prick test results were obtained from the patient's health record.

Results: The study was attended by the mothers of 49 boys and 51 girls (age 6 months to 15 years old) with atopic dermatitis. When the patients were grouped according to the SCORAD score, 48 had mild, 49 had moderate, and three had severe atopic dermatitis. The frequency of washing with bath was high in patients grouped according to SCORAD $(p=0.001)$. Patients with severe atopic dermatitis more often take a bath in the winter than those with mild and moderate atopic dermatitis (22.45\%) $(p=0.034)$. No significant relationship was found between moisturizer use, bathing frequency, and bath products used and severity of atopic dermatitis.

Conclusion: Bathing can be more effective than taking a shower. In the treatment of atopic dermatitis, the use of moisturizers, type of bathing, and bathing products used in addition to medications may be important and must be evaluated comprehensively.

Keywords: Atopic dermatitis, bath, shower, eczema, SCORing atopic dermatitis

Sorumlu Yazar/Corresponding Author: Esra Yücel E-mail: esraozek@yahoo.com

Başvuru/Submitted: 10.08.2020 • Revizyon Talebi/Revision Requested: 04.09.2020 • Son Revizyon/Last Revision Received: 15.09.2020 • Kabul/Accepted: 03.11.2020 


\section{Gíiş̧}

Atopik dermatit (AD) özellikle çocuklarda sık görülen kronik, tekrarlayıcı, kaşıntılı ve enflamatuvar bir deri hastalığıdır $(1,2)$. Atopik dermatit sıklığı giderek artmakta olup; bu artıştan endüstriyel gelişimle birlikte yaşam tarzındaki değişiklikler, artmış çevre kirliliği ve sigara dumanı maruziyeti gibi çevresel faktörler sorumlu tutulmaktadır $(3,4)$. Genel ortalamaya bakıldığında Avrupa'da prevalans \%14,2, Orta Amerika'da ise prevalans $\% 18,2$ bildirilmiştir (5). Ülkemizde yapılan çeşitli çalışmalarda ise farklı sonuçlar bildirilmekle beraber çocukluk çağında anket yöntemi kullanılarak yapılan çalışmalarda yaşam boyu ve son 12 aydaki AD sıklığının sırayla \%10-20 ve \%5-10 arasında değiştiği, çocuklarda doktor tanılı $A D$ ve fizik muayenede $A D$ sıklığının \%5'ten az olduğu söylenebilir (6).

Atopik dermatit genetik yatkınlık, immün disregülasyon, epidermal bariyer fonksiyon bozukluğu ve çevresel faktörlerin etkileşimiyle oluşmaktadır (7-9). Patogenezde derinin bariyer yapısı ve fonksiyonundaki bozukluklar ile deride gelişen enflamasyon rol oynamaktadır (6). Bu nedenle atopik dermatitte cilt kuruluğu hayatın ilk günlerinden itibaren görülür ve $A D$ 'nin genel bulgularındandır (10-12). Bariyer fonksiyonu bozuk olan, kuru, aşırı duyarlı ve geçirgen olan derinin hidrasyonu, düzenli olarak nemlendirici/emolyentler ile desteklenmelidir $(6,13)$. Cildin nemlendirilmesi atopik dermatitin idame tedavisindeki en önemli yaklaşımlardan biridir. Nemlendiriciler düzenli aralıklarla ve yeterli miktarda kullanıldığı zaman cilt bariyerini iyileştirir, cildin tahriş edici etkenlere duyarlılığını azaltır.

Banyo yapmak cilt için gerekli hidrasyonu sağlar, ayrıca zararlı tahriş edici maddeleri ve alerjenleri giderir. Bununla birlikte fazla yıkanma, stratum korneum proteinleri ve esansiyel lipitleri ortadan kaldırabilir, kullanılan ürünlere bağlı ciltte tahriş gelişebilir. Bu nedenle, cilt bariyer fonksiyonunu korumak ve egzama şiddetini en aza indirmek için gereken ideal banyo sıklığı ve süresinin belirlenmesi önem taşımaktadır. Bu çalışmada AD tanılı hastalarda banyo alışkanlıklarının ve nemlendirici kullanımının hastalığın şiddetine etkisi ve ailelerin bu konudaki tutumlarının araştırılması amaçlandı.

\section{YÖNTEM VE GEREÇLER}

\section{Hasta Seçimi}

Eylül-Aralık 2018 tarihleri arasında Çocuk Alerji ve İmmünoloji polikliniğine ilk kez başvuran atopik dermatitli 6 ay-18 yaş aralığında çocuğu olan ve anketi doldurmaya gönüllü olan Türkçe okumayı ve yazmayı bilen tüm anneler çalışmaya dahil edildi.

Atopik Dermatit tanısı Hanifin- Rajka kriterlerine göre konuldu (14).

6 aydan küçük ya da 18 yaşından büyük hastaların anneleri, atopik dermatit dışında egzamatöz hastalığı ya da immün yetmezliği olan hastaların anneleri, anket doldurmayı kabul etmeyen anneler ile okur yazar olmayanlar çalışmaya dahil edilmedi.

\section{Anket ve Verilerin Toplanması}

Hastalara ait veriler ve yapılmış olan laboratuvar tetkikleri (serum total immunglobulin (Ig) E, eozinofil yüzdesi ve deri delme testi sonucu) hastane sisteminden elde edildi.

Annelere banyo sıklığı, yıkanma şekli, banyo süresi, banyoda kullanılan ürünler ve nemlendirici kullanımı ile ilgili ve ailenin demografik yapısı ile ilgili sorular (kardeş sayısı, evde yaşayan kişi sayısı vb.) içeren bir anket doldurtuldu. Çalışma öncesi rastgele seçilen on hasta annesine anket doldurularak soruların anlaşılabilir olduğundan emin olundu.

\section{Atopik Dermatit Şiddetinin Değerlendirilmesi}

Anketi doldurmayı kabul eden annelerin çocuklarının AD ağırlığını belirlemek amacı ile Scorad Indeks European TASK Force On Atopic Dermatitis (SCORAD) İndeksi belirlendi. SCORAD indeksi aynı araştırıcı tarafindan A) Tutulum alanı; B) Etkilenme şiddeti; C) Kaşıntı ve uyku kaybı; Bu 3 ana bileşenden elde edilen skor $\mathrm{A} / 5+7 \mathrm{~B} / 2+\mathrm{C}$ olarak hesaplandı ve total SCORAD skoru elde edildi. Total SCORAD skoru $25^{\prime}$ in alt hafif, 25-50 puan arası orta, 50 puanın üstü ise ağır $A D$ olarak kabul edildi (6).

\section{İstatistiksel Metot}

İstatistiksel analizler SPSS versiyon 17.0 programı yardımıyla gerçekleştirildi. Tanımlayıcı analizler sunulurken ortalama, standart sapma, ortanca değerler kullanıldı. Kategorik değişkenler arasındaki ilişki 2x2 gözlerde Pearson Ki Kare ve Fisher's Exact Testleri ile karşılaştırıldı. Normal dağılım göstermeyen (non parametrik) değişkenler iki grup arasında değerlendirilirken Mann Whitney U Testi, ikiden fazla grup arasında değerlendirilirken

Kruskal Wallis Testi kullanıldı. P-değerinin 0,05 'in altında olduğu durumlar istatistiksel olarak anlamlı sonuçlar şeklinde değerlendirildi.

\section{BULGULAR}

Çalışmaya AD'li 49 erkek ve 51 kız hastanın toplam 100 annesi alındı. Ankete katılan annelerin ortalama anne yaşı 31,80 \pm 7,35 yıl idi. Ankete katılan annelerden sadece 7'si çalışırken diğerleri ev hanımı idi. Annelerin \%32'si ilköğretim mezunu iken diğerleri lise/üniversite mezunu idi. Ortalama aylık gelir ise anket dolduran annelerin sadece $\% 14$ 'ünde 3000 lira ve üzerinde idi.

Çocukların yaş ortancası 3,5 yıl idi. Hastaların demografik özellikleri Tablo 1'de verildi.

Çocukların banyo sıklıklarının kış aylarında azaldığı görülürken yaz aylarında çocukların \%70'nin her gün düzenli banyo yaptğı görüldü. Hastalardan 13'ü hiç nemlendirici kullanmıyordu (Tablo 2).

Hastalar SCORAD skorlarına göre çocukların banyo ve nemlendirici kullanma alışkanlıkları karşılaştırıldığında yıkanma şekli ve kış aylarında yıkanma sıklığı arasında istatistiksel olarak anlamlı fark tespit edildi ( $p=0,001, p=0,034)$ (Tablo 3). 
Tablo 1: Hastaların demografik, klinik ve laboratuvar özellikleri $(n=100)$

\begin{tabular}{|c|c|c|}
\hline & Ortalama $\pm S D$ & Ortanca \\
\hline Hasta yaşı (yıl) & $4,16 \pm 3,11$ & 3,50 \\
\hline Anne yaşı (yıl) & $31,8 \pm 7,35$ & 32,0 \\
\hline Yakınma başlangıç yaşı (yıl) & $1,95 \pm 2,35$ & 1,00 \\
\hline Teşhis edilme yaşı (yıl) & $2,08 \pm 2,31$ & 1,25 \\
\hline Kardeş sayısı & $1,35 \pm 1,27$ & 1,00 \\
\hline Evde yaşayan kişi sayısı & $4,35 \pm 1,23$ & 4,00 \\
\hline Kan eozinofil seviyesi (\%) & $5,04 \pm 2,79$ & 5,05 \\
\hline Serum total Ig E düzeyi & $546,25 \pm 1312,83$ & 107,50 \\
\hline \multirow[t]{2}{*}{ Total SCORAD skoru } & $27,40 \pm 11,07$ & 25,20 \\
\hline & $\mathbf{N}$ & $\%$ \\
\hline Eşlik eden ek alerjik hastalık & 17 & 17 \\
\hline Ailede atopi varlığı & 26 & 26 \\
\hline \multicolumn{3}{|l|}{ SCORAD skoru } \\
\hline Hafif & 48 & 48 \\
\hline Orta & 49 & 49 \\
\hline Ağır & 3 & 3 \\
\hline $\begin{array}{l}\text { Deri delme testinde saptanan } \\
\text { solunum alerjen duyarlılığı }\end{array}$ & 28 & 28 \\
\hline $\begin{array}{l}\text { Deri delme testinde saptanan besin } \\
\text { alerjen duyarlılığı }\end{array}$ & 12 & 12 \\
\hline
\end{tabular}

\section{TARTIŞMA}

Bu çalışmada AD'in SCORAD skoruna göre ağırlığı ile banyo alışkanlıkları ve nemlendirici ürün kullanımı arasındaki ilişki değerlendirildi. Benzer çalışmalarda farklı sonuçlar elde edilmekle beraber $(15,16)$ bizim çalışmamızda SCORAD skoruna göre AD'in ağırlığı ile yıkanma şekli ve kış aylarında banyo sıklığı arasında anlamlı ilişki tespit edildi. Ağır egzaması olanların tamamı duş alma şeklinde yıkanırken, SCORAD skoru hafif olanların $\% 14,5^{\prime} \mathrm{i}$ ve orta olanların ise $\% 16,3$ 'ünün duş alarak yıkandığı tespit edildi ( $p=0,001)$. Bulgularımıza göre duş almak yerine banyo yapmanın cildin daha iyi nemlenmesine ve hastalığın daha hafif olmasına yol açtığı düşünülebilir. Ancak ağır olgu sayısının az olması genelleme yapılmasını engellemektedir. Bu konuda daha fazla randomize kontrollü çalışmalara gereksinim vardır.

Bilindiği üzere yaz aylarında terlemenin de etkisi ile AD alevlenmeleri daha fazla görülmektedir ve birçok çalışma da yaz aylarındaki banyo alışkanlıklarını değerlendirmiştir (17-19). Japonya'da yaz aylarında yapılan bir çalışmada AD'li 58 çocuk değerlendirilmiş ve her gün banyo yapmanın özellikle ağır $A D$ 'si olanlarda daha çok iyileşmeye neden olduğu gösterilmiştir (17). Başka bir çalışmada ise yaz aylarında her gün banyo yapanların SCORAD skorlarında daha anlamlı düşme olduğu bildirilmiştir (18). Ancak çalışmamızda farklı olarak yaz aylarındaki banyo sayısı ve sıklığı ile SCORAD ağırlığı arasında anlamlı ilişki tespit edilmedi. Bu durumun hastalarımızın yaz aylarında her gün banyo yapma sıklığının yüksek olmasına bağlı olabileceğini düşünmekteyiz.
Tablo 2: Atopik Dermatitli çocukların banyo ve nemlendirici uygulama özellikleri

\begin{tabular}{|c|c|c|}
\hline & $\mathbf{n}$ & $\%$ \\
\hline \multicolumn{3}{|l|}{ Yıkanma şekli } \\
\hline Banyo & 82 & $(82,00)$ \\
\hline Duş & 18 & $(18,00)$ \\
\hline \multicolumn{3}{|l|}{ Kış aylarında yıkanma süresi } \\
\hline $5 \mathrm{dk} . \mathrm{kısa}$ & 12 & $(12,00)$ \\
\hline 5-15 dk. arası & 82 & $(82,00)$ \\
\hline $15-30 \mathrm{dk}$. arası & 6 & $(6,00)$ \\
\hline \multicolumn{3}{|l|}{ Kış aylarında yıkanma sıklığı } \\
\hline Haftada 1 & 22 & $(22,00)$ \\
\hline Haftada 2-3 & 61 & $(61,00)$ \\
\hline Her gün & 17 & $(17,00)$ \\
\hline \multicolumn{3}{|l|}{ Yaz aylarında yıkanma süresi } \\
\hline $5 \mathrm{dk}$. kısa & 15 & $(15,00)$ \\
\hline 5-15 dk. arası & 67 & $(67,00)$ \\
\hline $15-30 \mathrm{dk}$. arası & 13 & $(13,00)$ \\
\hline 30 dk. fazla & 5 & $(5,00)$ \\
\hline \multicolumn{3}{|l|}{ Yaz aylarında yıkanma sıklığı } \\
\hline Haftada 2-3 & 23 & $(23,00)$ \\
\hline Her gün & 70 & $(70,00)$ \\
\hline Günde 1 den fazla & 7 & $(7,00)$ \\
\hline \multicolumn{3}{|l|}{ Yıkanma sırasında kullanılan banyo ürünü } \\
\hline Bebek şampuanı & 40 & $(40,00)$ \\
\hline Kalıp sabun & 8 & $(8,00)$ \\
\hline Kozmetik içeren şampuan & 4 & $(4,00)$ \\
\hline Kozmetik içermeyen şampuan (sindet) & 48 & $(48,00)$ \\
\hline \multicolumn{3}{|l|}{ Banyo sonrası nemlendirici kullanımı } \\
\hline Evet & 87 & $(87,00)$ \\
\hline Hayır & 13 & $(13,00)$ \\
\hline \multicolumn{3}{|l|}{ Nemlendirici kullanım sıklığı } \\
\hline Haftada 1 ya da daha az & 7 & $(8,04)$ \\
\hline Haftada 2-3 kez & 32 & $(36,70)$ \\
\hline Her gün & 37 & $(42,50)$ \\
\hline Günde 1'den fazla & 11 & $(12,60)$ \\
\hline \multicolumn{3}{|l|}{ Nemlendirme amacıyla kullanılan ürün } \\
\hline Bebe yağı & 16 & $(18,39)$ \\
\hline Kozmetik içerikli nemlendirici & 2 & $(2,30)$ \\
\hline Atopik ciltlere uygun nemlendirici & 50 & $(57,47)$ \\
\hline Vazelin & 10 & $(11,49)$ \\
\hline Zeytinyağı & 5 & $(5,75)$ \\
\hline Diğer & 4 & $(4,60)$ \\
\hline
\end{tabular}


Tablo 3: SCORAD skoruna göre sınıflandırılan atopik dermatitli çocukların banyo ve nemlendirici uygulama özellikleri

\begin{tabular}{|c|c|c|c|c|c|c|c|}
\hline & \multicolumn{6}{|c|}{ SCORAD skoru } & \multirow{3}{*}{ p değeri } \\
\hline & \multicolumn{2}{|c|}{ Hafif $(n=48)$} & \multicolumn{2}{|c|}{ Orta $(n=49)$} & \multicolumn{2}{|c|}{ Ciddi $(n=3)$} & \\
\hline & $\mathbf{n}$ & $\%$ & $\mathrm{n}$ & $\%$ & $\mathbf{n}$ & $\%$ & \\
\hline \multicolumn{8}{|l|}{ Yıkanma şekli } \\
\hline Banyo & 41 & 85,42 & 41 & 83,67 & 0 & ,00 & 0,001 \\
\hline Duş & 7 & 14,58 & 8 & 16,33 & 3 & 100,00 & \\
\hline \multicolumn{8}{|l|}{ Kış aylarında yıkanma Süresi } \\
\hline $5 \mathrm{dk} . \mathrm{kısa}$ & 6 & 12,50 & 5 & 10,20 & 1 & 33,33 & 0,814 \\
\hline 5-15 dk. arası & 39 & 81,25 & 41 & 83,67 & 2 & 66,67 & \\
\hline $15-30 \mathrm{dk}$. arası & 3 & 3 & 3 & 6,12 & 0 & , 00 & \\
\hline \multicolumn{8}{|l|}{ Kış aylarında yıkanma sıklığı } \\
\hline Haftada 1 & 10 & 20,83 & 11 & 22,45 & 1 & 33,33 & 0,034 \\
\hline Haftada 2-3 & 34 & 70,83 & 27 & 55,10 & 0 & ,00 & \\
\hline Her gün & 4 & 8,33 & 11 & 22,45 & 2 & 66,67 & \\
\hline \multicolumn{8}{|l|}{ Yaz aylarında yıkanma süresi } \\
\hline $5 \mathrm{dk} . \mathrm{kısa}$ & 9 & 18,75 & 5 & 10,20 & 1 & 33,33 & 0,622 \\
\hline 5-15 dk. arası & 31 & 64,58 & 34 & 69,39 & 2 & 66,67 & \\
\hline $15-30 \mathrm{dk}$. arası & 7 & 14,58 & 6 & 12,24 & 0 & ,00 & \\
\hline 30 dk. fazla & 1 & 2,08 & 4 & 2,08 & $(8,16)$ & 0 & $(, 00)$ \\
\hline \multicolumn{8}{|l|}{ Yaz aylarında yıkanma sıklığı } \\
\hline Haftada 2-3 & 13 & 27,08 & 10 & 20,41 & 0 & ,00 & 0,736 \\
\hline Her gün & 32 & 66,67 & 35 & 71,43 & 3 & 100,00 & \\
\hline Günde 1 den fazla & 3 & 6,25 & 4 & 8,16 & 0 &, 00 & \\
\hline \multicolumn{8}{|l|}{ Banyoda kullanılan ürün } \\
\hline Bebek şampuanı & 17 & 35,42 & 20 & 40,82 & 3 & 100,00 & 0,435 \\
\hline Kalıp sabun & 4 & 8,33 & 4 & 8,16 & 0 & ,00 & \\
\hline Kozmetik içeren şampuan & 3 & 6,25 & 1 & 2,04 & 0 &, 00 & \\
\hline Kozmetik içermeyen şampuan (sindet) & 24 & 50,00 & 24 & 48,98 & 0 & ,00 & \\
\hline \multicolumn{8}{|l|}{ Nemlendirici ürün kullanımı } \\
\hline Evet & 42 & 87,50 & 43 & 87,76 & 2 & 66,67 & 0,568 \\
\hline Hayır & 6 & 12,50 & 6 & 12,24 & 1 & 33,33 & \\
\hline \multicolumn{8}{|l|}{ Nemlendirme amacıyla kullanılan ürün } \\
\hline Bebe yağı & 7 & 16,67 & 9 & 20,93 & 0 &, 00 & 0,726 \\
\hline Kozmetik içeren nemlendirici & 0 &, 00 & 2 & 4,65 & 0 &, 00 & \\
\hline Atopik ciltlere uygun nemlendirici & 26 & 61,90 & 22 & 51,16 & 2 & 100,00 & \\
\hline Vazelin & 5 & 11,90 & 5 & 11,63 & 0 & ,00 & \\
\hline Zeytinyağı & 1 & 2,38 & 4 & 9,30 & 0 & ,00 & \\
\hline Diğer & 3 & 7,14 & 1 & 2,33 & 0 & ,00 & \\
\hline \multicolumn{8}{|l|}{ Nemlendirici kullanım sıklığı } \\
\hline Haftada 1 den az & 5 & 11,63 & 3 & 6,98 & 0 &, 00 & 0,787 \\
\hline Haftada 2-3 & 18 & 41,86 & 13 & 30,23 & 1 & 50,00 & \\
\hline Her gün & 16 & 37,21 & 20 & 46,51 & 1 & 50,00 & \\
\hline Günde 1 den fazla & 4 & 9,30 & 7 & 16,28 & 0 & ,00 & \\
\hline
\end{tabular}


Çalışmamızda diğer araştırmalardan farklı olarak kış aylarındaki banyo alışkanlıkları da sorgulandı ve banyo sayısı ile SCORAD skoru arasında ters ilişki saptandı. Buna göre her gün banyo yapanların SCORAD skorları daha yüksek bulundu. Skoru yüksek olanlar cilt sorunları nedeni ile daha fazla banyo yapıyor olabilirler. Ayrıca araştırmamızda AD'li 3 hastadan 2'sinin her gün banyo yapıyor olması bu sonucu etkileyebilir. Kış aylarında banyo alışkanlığının değerlendirildiği bir çalışmada hastaların çoğunluğunun kış aylarında sadece duş aldığını ve duş sıklığı ile $A D$ ağırlığı arasında da herhangi bir ilişki tespit edilmediği bildirilmiştir $(16,20)$.

Uluslararası rehberler AD'li hastalarda ideal banyo süresinin ortalama 5-15 dakika arasında olması gerektiğini belirtmektedir $(21,22)$. Banyoda geçirilen süre ne kadar uzarsa, muhtemelen artan cilt hidrasyonuna bağlı olarak AD şiddetinde de azalma olacağı öne sürülmüştür. Ancak diğer taraftan da uzun süre suya maruz kalındığında ciltteki epidermis tabakasındaki Filagrin seviyelerinin azaldığı bildirilmiştir (15). Çalışmamızda ise banyo süresi ile $A D$ ağırlığı arasında anlamlı bir ilişki tespit edilmedi.

Çalışmamızda nemlendirici kullanımı, sıklığı ile AD ağırlığı arasında anlamlı ilişki bulunmadı. Bu durum araştırmanın kesitsel olması ve geriye dönük verilere dayanmasından kaynaklanabilir. Ancak biliyoruz ki, AD tedavisinin her basamağında derinin nemlendirilmesi gereklidir ve derinin düzenli olarak her gün nemlendirilmesi tedavinin temelini oluşturmaktadır $(6,13)$. Nemlendiriciler günde iki kez ve banyodan hemen sonra üç dakika içinde sürülmelidir. Nemlendirici seçimi hastanın yaşına, uyumuna, hastalık aktivitesine, ilaç etkinliğine, güvenlik verilerine ve tedavi maliyetine göre yapılmalıdır. Nemlendirici kullanımının AD şiddetini azalttı̆̆ birçok çalışmada gösterilmiştir (23-27). Ancak nemlendirici çeşidi, kullanma sıklığı ve miktarı ile ilgili çalışmalar çok kısıtıdır. Bir çalışmada üre bazlı preparatların birinci basamak tedavi olarak tercih edilebileceği bildirilmiştir (27). Çalışmamızda AD şiddeti ile ailenin tercih ettiği nemlendirici çeşitleri arasında fark saptanmamıştır ve \%13 hastanın tedavinin ilk ve en önemli basamağı olan nemlendiriciyi kullanmadığı görülmüştür.

Çalışmanın kısıtııı̆ı anket çalışması olması nedeni ile katılımcıların verdikleri cevapların doğrulanamaması ve çok geniş sayıda hastaya uygulanamamış olmasıdır.

Sonuç olarak, çalışmamızda banyo şeklinde yıkanmanın ağır olgularda daha sık olduğu tespit edilmiştir ancak banyo sıklığı, süresi, nemlendirici kullanımı, kullanılan nemlendirici çeşidi ve sıklığı ile AD ağırlığı arasında anlamlı fark saptanmamıştır. Atopik dermatit tedavisinde etkin banyo alışkanlıklarının ayrıntılı değerlendirilmesi gerekmektedir.

Etik Komite Onayı: Bu çalışma için etik komite onayı Sağlık Bilimleri Üniversitesi Okmeydanı Eğitim Araştırma Hastanesi Etik Kurul'undan alınmıştir. (984/2018)

Bilgilendirilmiş Onam: Katlımcılardan bilgilendirilmiş onam alınmıştır.

Hakem Değerlendirmesi: Dış bağımsız.
Yazar Katkıları: Çalışma Konsepti/Tasarım- E.Y., D.Ö.; Veri Toplama- D.Y.K.; Veri Analizi/Yorumlama- E.Y., D.Ö., Ö.F.B.; Yazı Taslağı- D.Y.K.; İ̧eriğin Eleştirel İncelemesi- E.Y., D.Ö., Ö.F.B.; Son Onay ve Sorumluluk- D.Y.K., E.Y., D.Ö., Ö.F.B.; Malzeme ve Teknik Destek- D.Y.K.; Süpervizyon- E.Y., D.Ö.

Çıkar Çatışması: Yazarlar çıkar çatışması beyan etmemişlerdir.

Finansal Destek: Yazarlar finansal destek beyan etmemişlerdir.

Ethics Committee Approval: Ethics committee approval for this study was obtained from the Ethics Committee of Health Sciences University Okmeydanı Training and Research Hospital. (984/2018)

Informed Consent: Written consent was obtained from the participants.

Peer Review: Externally peer-reviewed.

Author Contributions: Conception/Design of Study- E.Y., D.Ö.; Data Acquisition- D.Y.K.; Data Analysis/Interpretation- E.Y., D.Ö., Ö.F.B.; Drafting Manuscript- D.Y.K.; Critical Revision of Manuscript- E.Y., D.Ö., Ö.F.B.; Final Approval and Accountability- D.Y.K., E.Y., D.Ö., Ö.F.B.; Technical or Material Support- D.Y.K.; Supervision- E.Y., D.Ö.

Conflict of Interest: Authors declared no conflict of interest.

Financial Disclosure: Authors declared no financial support.

\section{KAYNAKLAR/REFERENCES}

1. Katayama I, Kohno Y, Akiyama K, et al: Japanese guidelines for atopic dermatitis. J Am Acad Dermatol 2014;70:338-98.

2. Weidinger $S$, Novak N. Atopic dermatitis. Lancet 2016;387(10023):1109-22.

3. Morales Suárez-Varela M, García-Marcos L, Kogan MD, Lopis González A, Martínez Gimeno A, Aguinaga Ontoso I, et al. Parents' smoking habit and prevalence of atopic eczema in 6-7 and 1314 year-old school children in Spain. ISAAC phase III. Allergol Immunopathol (Madr) 2008;36(6):336-42.

4. Wang IJ, Chen SL, Lu TP, Chuang EY, Chen PC. Prenatal smoke exposure, DNA methylation, and childhood atopic dermatitis. Clin Exp Allergy 2013;43(5):535-43.

5. Draaisma E, Garcia-Marcos L, Mallol J, Sole D, Perez-Fernandez V, Brand PLP. The EISL Study Group. A multinational study to compare prevalence of atopic dermatitis in the first year of life. Pediatr Allergy Immunol 2015;26(4):359-366.

6. Harmancı K, Uysal P, Arga M, et al. Atopik dermatit tanı ve tedavisine yaklaşım: ulusal rehber 2018 ve ürtiker tanı ve tedavisi güncel durum raporu. Asthma Allergy Immunol 2018;16(Suppl 2):1-95.

7. Brunner PM, Leung DYM, Guttman-Yassky E. Immunologic, microbial, and epithelial interactions in atopic dermatitis. Ann Allergy Asthma Immunol 2018;120(1):34-41.

8. Ahn K. The role of air pollutants in atopic dermatitis. J Allergy Clin Immunol 2014;134(5):993-9; discussion 1000.

9. Kim BE, Leung DYM. Significance of skin barrier dysfunction in atopicdermatitis. AllergyAsthma Immunol Res 2018;10(3):207-15.

10. Sargen MR, Hoffstad O, Margolis DJ. Warm, humid, and high sun exposure climates are associated with poorly controlled eczema: PEER (Pediatric Eczema Elective Registry) cohort, 2004-2012. J Invest Dermatol 2014;134(1):51-7. 
11. de Bruin Weller MS, Knulst AC, Meijer Y, Bruijnzeel-Koomen CA, Pasmans SG. Evaluation of the child with atopic dermatitis. Clin Exp Allergy 2012;42(3):352-62.

12. Muraro A, Lemanske RF, Hellings PW, Akdis CA, Bieber T, Casale TB, et al. Precision medicine in patients with allergic diseases: Airway diseases and atopic dermatitis-PRACTALL document of the European Academy of Allergy and Clinical Immunology and the American Academy of Allergy, Asthma \& Immunology. J Allergy Clin Immunol 2016;137(5):1347-58.

13. Ertam I, Su Ö, Alper S, Sarıcaoğlu H, Karadağ AS, Odyakmaz Demirsoy $E$, et al. Türkiye atopik dermatit tanı ve tedavi kılavuzu-2018. Turk Arch Dermatol Venereology 2018;52:6-23.

14. Hanifin JM, Rajka G. Diagnostic features of atopic dermatitis. Acta DermatoVenereol 1980:(Suppl 92):44-7.

15. Koutroulis I, Pyle T, Kopylov D, Little A, Gaughan J, Kratimenos P. The Association Between Bathing Habits and Severity of Atopic Dermatitis in Children. Clinical Pediatrics 2016;55(2):176-81.

16. Koutroulis I, Petrova K, Kratimenos P, Gaughan J. Frequency of bathing in the management of atopic dermatitis: to bathe or not to bathe? Clin Pediatr (Phila) 2014;53(7):677-81.

17. Kameyoshi $Y$, Tanaka T, Mochizuki M, Koro O, Mihara S, Hiragun $\mathrm{T}$, et al. Taking showers at school is beneficial for children with severer atopic dermatitis. Arerugi 2008;57(2):130-7.

18. Kim H, Ban J, Park M-R, Kim D-S, Kim H-Y, Han Y, et al. Effect of bathing on atopic dermatitis during the summer season. Asia Pac Allergy 2012;2(4):269-74.
19. Mochizuki H, Muramatsu R, Tadaki H, Mizuno T, Arakawa $H$, Morikawa A. Effects of Skin Care with Shower Therapy on Children with Atopic Dermatitis in Elementary Schools. Pediatric Dermatology 2009;26(2):223-5.

20. Hon KLE, Leung TF, Wong Y, So HK, Li AM, Fok TF. A survey of bathing and showering practices in children with atopic eczema. Clinical and Experimental Dermatology 2005;30(4):351-4.

21. Schneider L, Tilles S, Lio P, Boguniewicz M, Beck L, LeBovidge J, et al. Atopic dermatitis: a practice parameter update 2012. J Allergy Clin Immunol 2013;131(2):295-9.

22. Ring J, Alomar A, Bieber T, Deleuran M, Fink-Wagner A, Gelmetti C, et al. Guidelines for treatment of atopic eczema (atopic dermatitis) Part 1. J Eur Acad Dermatol Venereol 2012;26(8):1045-60.

23. Purnamawati S, Indrastuti N, Danarti R, Saefudin T. The Role of Moisturizers in Addressing Various Kinds of Dermatitis: A Review. Clin Med Res 2017;15(3- 4):75-87.

24. Kraft JN, Lynde CW. Moisturizers: what they are and a practical approach to product selection. Skin Therapy Lett 2005;10(5):1-8.

25. Krakowski AC, Eichenfield LF, Dohil MA. Management of atopic dermatitis in the pediatric population. Pediatrics 2008;122(4):81224.

26. Lindh JD, Bradley M. Clinical Effectiveness of Moisturizers in Atopic Dermatitis and Related Disorders: A Systematic Review. Am J Clin Dermatol 2015;16(5):341-59. 